Thomas. HCA Healthcare Journal of Medicine (2020) 1:COVID-19.

\title{
Music
}

\section{COVID-19 with Congruent Affect}

Mitchell Thomas ${ }^{1}$

\section{Abstract}

\section{Description}

Music is a vehicle of capturing an individual's experiences: a new beginning, a broken heart, complete joy, and even catharsis. Before deciding to embark on my path in medicine, music was my interest. Creating music is my therapeutic method of relieving stress, providing a productive outlet when coping with my stressors, and allowing me to focus on becoming a better student doctor. It has carried me through tough times and continues to do so. This instrumental song I wrote represents how I felt as a second-year medical student going through the COVID-19 pandemic; from being isolated in a state away from family, studying for some of the most important board exams we will take, to moving back home, starting clinical rotations, and learning to care for patients as an incoming third-year medical student through this paradigm shift in healthcare.

\section{Keywords}

COVID-19; SARS-CoV-2; coronavirus; music; humanities; occupational stress; mindfulness
Author affiliations are listed at the end of this article.

Correspondence to: Mitchell Thomas 10007 Logan Falls Ct. Jacksonville FL 32222 (mthomas02@carolinas. vcom.edu)

To listen click here.

\section{Conflicts of Interest}

The author declares he has no conflicts of interest.

\section{Author Affiliation}

1. Edward Via Virginia College of Osteopathic Medicine 